\title{
Treatment of Fisher's Variant of Guillain Barré Syndrome by Exchange Transfusion
}

\author{
ALLAN T. IRVINE and JOHN TIBBLES
}

SUMMARY: $A$ case of Fisher's variant of Guillain Barré Syndrome is presented. Treatment with exchange transfusion coincided with clinical improvement. This is the first case of Fisher's variant treated in this manner.

RESUME: Nous présentons un cas de la variante de Fisher du Syndrome de Guillain Barré. Le traitement par transfusion d'échange coincidait avec une amélioration clinique. Il s'agit du premier cas de cette variante ainsi traité.
From the Department of Paediatrics, Dalhousie University and the Izaak Walton Killam Hospital for Children, Halifax, Nova Scotia, Canada.

Reprint requests to Dr. J.A.R. Tibbles, I.W.K. Hospital for Children, Halifax, Nova Scotia, Canada, B3J 3 G9.
Plasma exchange has been used with success in the treatment of acute polyneuropathy (Brettle et al., 1978) and chronic relapsing idiopathic polyneuropathy (Levy et al., 1979; Fowler et al., 1979; Server et al., 1979). There' is evidence to implicate both a cellular and humoral component in the Guillain Barré Syndrome (G.B.S.). Myelinotoxic antibodies of the $1 \mathrm{gM}$ class have been demonstrated in the sera of patients with this disease, suggesting that antibody formation may play a pathologic role in G.B.S. This has led to the use of plasma exchange and hemodialysis as a form of treatment; the latter unsuccessfully. (Server et al., 1979). We report a case of Fisher's syndrome (ataxic cranial polyneuritis), a variant of G.B.S., treated by exchange transfusion.

A six year old boy presented with a seven day history of malaise and headache. Two days prior to admission he developed double vision. On examination of the extra-ocular movements there was bilateral impairment of abduction. The remainder of the cranial nerves were normal. There was slight weakness of neck flexion and pelvic girdle musculature. Muscle stretch reflexes were depressed but elicitable. He had an intention tremor and his gait was ataxic. Sensory examination was normal. Complete blood count, electrolytes and a CT scan were normal. Lumbar puncture demonstrated one white cell and a protein of $.32 \mathrm{~g} / 1$.

Over the next 48 hours he developed a progressive external ophthalmoplegia, ptosis, bilateral facial weakness and palatal weakness. Strength in the arms was diminished (Grade 4/5). Leg movements were just possible, but he was unable to bear weight. There was generalized areflexia. Vibration sense was absent up to the fourth thoraic dermatome. Vital capacity was $40 \%$ of predicted normal.

Motor and sensory conduction velocities in the peroneal, median and sural nerves were normal, but there was a decreased amplitude of response in the peroneal nerve. In conjunction with the clinical findings this suggested a proximal nerve conduction block. Prednisone $40 \mathrm{mg}$. daily $(2 \mathrm{mg}$. per kilo) was commenced. Cerebrospinal fluid examination on the 4th day showed a protein of $.78 \mathrm{~g} / \mathrm{l}$ and no white blood cells.

By the 5th hospital day there was a complete external ophthalmoplegia with bilateral ptosis and facial weakness. Respiration was mainly diaphragmatic. The legs were completely paralysed; strength in the arms further reduced (Grade 2/5). Vital capacity was unchanged, blood gases were normal and there was no respiratory distress.

A series of three, two volume whole blood, exchange transfusions were performed on the 5th, 6th and 7th hospital days. Following each exchange there was progressive improvement in muscle strength. Toe movements were possible after the second transfusion. Horizontal eye movements returned except for right eye abduction. The ptosis and facial weakness improved.

On the 9th day vital capacity was $60 \%$ of normal. Sensory examination was unchanged. Electromyography with needle examination showed no evidence of denervation. Over the following week there was complete resolution of the cranial nerve findings. Strength in the arms returned to normal, but the legs were still weak (Grade 4/5). Serial complete blood counts, creatine phosphokinase, urea and creatinine were normal. An electrocardiogram showed right axis deviation, and terminal conduction delay. Acute and convalescent titres 
for Epstein-Barr virus and Cytomegalovirus were normal. Walking unaided was possible by the 24th hospital day, but he was still areflexic at 5 weeks. The indication for exchange transfusion in this patient was clinical deterioration to a point where ventilatory assistance could be anticipated.

Recovery in this patient during and after the use of exchange transfusion may have been fortuitous, but the temporal sequence of improvement with exchange transfusion in a patient who had been deteriorating favors a cause and effect relationship. Despite the disappearance of myelin basic protein in chronic relapsing idiopathic polyneuritis with plasma exchange (Server et al., 1979) great caution should be used in extrapolating results from a few individual case reports. If myelinotoxic antibody plays a pathologic role in G.B.S., proof that its removal is beneficial will be that clinical improvement correlates with a fall in antibody level, either from plasma exchange transfusion or exchange transfusion, and also that relapses are associated with a rise in the antibody level.

This report of a further case of acute polyneuritis treated by plasma removal emphasizes its possible role in treatment. In the future it will be important to document failures as well as successes to place this treatment in its proper perspective. It is likely that the organization of a prospective controlled trial of this costly form of management will be necessary.

\section{REFERENCES}

BRETTLE, R.P., GROSS, M., LEGG, N.J., LOCKWOOD, M., PALLIS, C., (1978) Treatment of acute polyneuropathy by plasma exchange. Lancet ii, 1100.

COOK, S.D., DOWNLING, P.C., MURRAY, M.R., WHITAKER, J.N., (1971) Circulating demyelinating factors in acute idiopathic polyneuropathy. Arch. Neurol. 24, 136 144.

FOWLER, H., VULPE, M., MARKS, G., EGOLF, C., DAU, P.C. (1979) Recovery from chronic progressive polyneuropathy after treatment with plasma exchange and cyclophosphamide. Lancet ii, 1193.

LEVY, R.L., NEWKIRK, R., OCHOA, J. (1979) Treating chronic relapsing Guillain Barré Syndrome by plasma exchange. Lancet 11, 259-260.

SERVER, A.C., LEFKOWITH, J., BRAINE, H., McK HANN, G.M. (1979) Treatment of chronic relapsing inflammatory polyradiculopathy by plasma exchange. Ann. Neurol. $6,258-260$. 